\title{
Ascites reinfusion dialysis of refractory ascites as a bridge to kidney and liver transplantation in a patient on hemodialysis
}

\author{
Kyung Yoon Chang ${ }^{1}$, Hyung Wook Kim ${ }^{1}$, Dong Chan Jin ${ }^{1}$, and Young Soo Kim²
}

\author{
${ }^{1}$ Division of Nephrology, \\ Department of Internal Medicine, \\ College of Medicine, St. Vincent's \\ Hospital, The Catholic University \\ of Korea, Suwon; ${ }^{2}$ Division of \\ Nephrology, Department of Internal \\ Medicine, College of Medicine, \\ Uijeongbu St. Mary's Hospital, \\ The Catholic University of Korea, \\ Uijeongbu, Korea
}

Received: April 7, 2015

Revised : June 19, 2015

Accepted: June 28, 2015

\section{Correspondence to}

Young Soo Kim, M.D.

Division of Nephrology,

Department of Internal Medicine,

College of Medicine, Uijeongbu

St. Mary's Hospital, The Catholic

University of Korea, 271

Cheonbo-ro, Uijeongbu 11765,

Korea

Tel: +82-31-820-3039

Fax: +82-31-847-2719

E-mail: dr52916@catholic.ac.kr
To the Editor,

The treatment of refractory ascites due to liver cirrhosis (LC) in end-stage renal disease (ESRD) without residual renal function is difficult. Kidney and liver transplantation is the gold standard therapy. Several procedures based on reinfusion of ascitic fluid such as intravenous reinfusion of concentrated ascites, extracorporeal ultrafiltration of ascitic fluid with peritoneal reinfusion, and ascitic fluid concentration with blood reinfusion during hemodialysis (HD) have been reported [1-4]. We herein describe an interesting case of ascites reinfusion dialysis that was performed as a bridge to kidney and liver transplantation.

A 41-year-old man presented with intradialytic hypotension and refractory ascites due to decompensated LC. He was scheduled to undergo kidney and liver transplantation. For effective HD, continuous flow control reinfusion of ascitic fluid into a dialyzer was designed to prevent intradialytic hypotension and control ultrafiltration [2]. A set of dialysis tubing was connected with the sterile three-way stopcock to draw out the ascites at the speed of 500 $\mathrm{mL} / \mathrm{hr}$ into the dialyzer to mix with the blood by the roller pump. Next, the mixed blood and ascites were infused into the systemic circulation during a
HD session. The ultrafiltration rate of the dialyzer was maintained at approximately $1 \mathrm{~L} / \mathrm{hr}$ to allow fluid removal from the blood and infused ascites in each 4-hour HD session. He underwent six sessions of ascites reinfusion dialysis over 3 weeks, after which he received a successful kidney and liver transplant. Changes in body weight and laboratory data of the patient are shown in Fig. 1.

There are several important clinical implications of ascites reinfusion dialysis into the dialyzer. First, this procedure was performed in order to remove adequate fluid without intradialytic hypotension. Second, the serum albumin level increased after this procedure. In this method, elevated serum albumin level might be due to the infused protein of the ascites into the systemic circulation during HD. As a result, increased serum oncotic pressure might have pulled the interstitial fluid into the intravascular space [5]. Third, although not observed in our case, the potential adverse outcomes should be kept in mind. Spontaneous bacterial peritonitis can occur, so we performed ascitic fluid analysis and prescribed empirical antibiotics with a third generation cephalosporin to prevent peritonitis. Forth, the patient can develop hepatic encephalopathy with sluggish speech and flapping tremors despite 

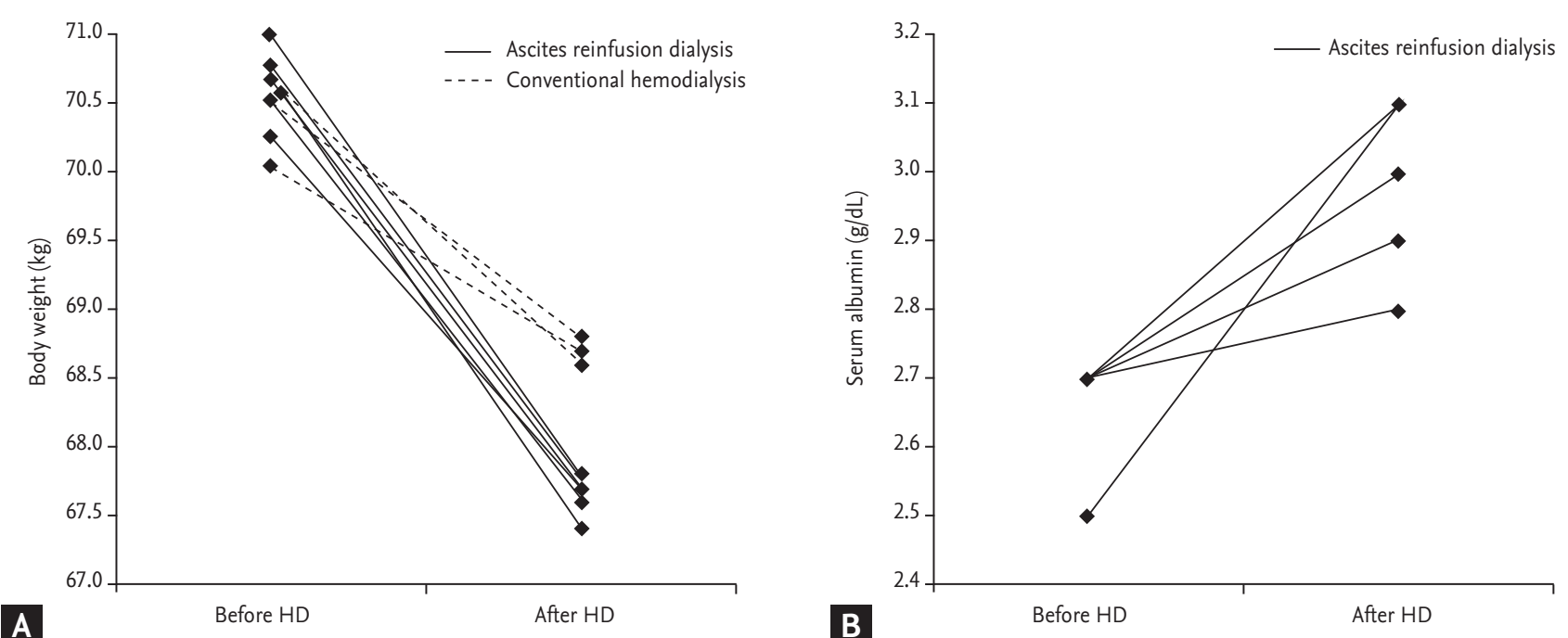

Figure 1. Changes in clinical data. Body weight changes in each hemodialysis (HD) session (A) and serum albumin levels (B) are shown before and after ascites reinfusion dialysis into the dialyzer during HD.

receiving lactulose. Because of these adverse effects, we could not perform aggressive ascites reinfusion dialysis. Therefore, we believe that ascites reinfusion dialysis into the dialyzer may be an alternative method as a bridge to kidney and liver transplantation.

Keywords: Ascites; Renal dialysis; Liver failure

\section{Conflict of interest}

No potential conflict of interest relevant to this article was reported.

\section{REFERENCES}

1. Albalate M, Lopez Garcia MD, Vazquez A, et al. Concentrated ascitic fluid reinfusion in cirrhotic patients: a simplified method. Am J Kidney Dis 1997;29:392-398.

2. Catalano C, Fabbian F, Di Landro D. Reinfusion and concentration of ascitic fluid during hemodialysis in a cirrhotic uremic patient. Am J Kidney Dis 1998;32:164167.

3. Daimon S, Yasuhara S, Saga T, Tokunaga S, Chikaki H, Dan K. Efficacy of extracorporeal ultrafiltration of ascitic fluid as a treatment of refractory ascites. Nephrol Dial Transplant 1998;13:2617-2623.

4. McGill RL, Bakos JR, Marcus RJ. Ascites reinfusion dialysis (ARD) for renal failure with refractory ascites. Clin Nephrol 2004;62:374-379.

5. Hsu TW, Chen YC, Wu MJ, Li AF, Yang WC, Ng YY. Reinfusion of ascites during hemodialysis as a treatment of massive refractory ascites and acute renal failure. Int $J$ Nephrol Renovasc Dis 2011;4:29-33. 